\title{
A study of etiology and outcome of preterm birth at a tertiary care centre
}

\author{
Shaveta Garg, Tajinder Kaur*, Ajayveer Singh Saran, Monu Yadav
}

\begin{abstract}
Department of Obstetrics and Gynecology, Maharishi Markandeshwar Institute of Medical Sciences and Research,
\end{abstract} Mullana, Ambala, Haryana, India

Received: 27 July 2017

Revised: 30 August 2017

Accepted: 01 September 2017

\author{
*Correspondence: \\ Dr. Tajinder Kaur, \\ E-mail: teji1978@rediffmail.com
}

Copyright: (c) the author(s), publisher and licensee Medip Academy. This is an open-access article distributed under the terms of the Creative Commons Attribution Non-Commercial License, which permits unrestricted non-commercial use, distribution, and reproduction in any medium, provided the original work is properly cited.

\begin{abstract}
Background: Preterm births are still the leading cause of perinatal mortality and morbidity. It is a major challenge in the obstetrical health care.

Methods: This study was conducted over a period of eight months from September 2016 till April 2017 at a tertiary care hospital. All patients who delivered a live baby before 37 weeks of gestation were included in the study.

Results: Present study was conducted on 100 eligible women out of which 7 delivered before 30 weeks but majority of them $(55 \%)$ delivered after 34 weeks of gestation. In our study, most of the patients $(66 \%)$ presented in active phase of labor which resulted in preterm birth of baby. The most common risk factor of preterm labor was genitourinary tract infections (34\%) followed by Preterm Premature rupture of membranes (22\%). Past obstetric history of preterm delivery and abortions also had a significant impact on the present pregnancy outcome.

Conclusions: Preterm labour and birth still have a high incidence causing significant neonatal mortality and morbidity as well as economic burden on family and hospital. The causes of preterm birth are multifactorial and modifiable. This incidence can be reduced by early identification of established risk factors, as revisited and reemphasized in our study, with the help of universal and proper antenatal care.
\end{abstract}

Keywords: Delivery, Preterm birth, Risk factors

\section{INTRODUCTION}

Preterm birth is defined as any birth before 37 completed weeks of gestation since first day of the female's last menstrual period, according to WHO. ${ }^{1}$ Preterm births still are the leading cause of perinatal mortality in developing countries. In addition to being a cause of mortality, preterm birth has long-term neurodevelopmental effects and higher risk of chronic diseases in adult life.

An estimated 14.9 million babies, $11.1 \%$ of all the live births worldwide were born preterm in $2010 .{ }^{1}$ In industrialized countries, $5-11 \%$ of infants are born before
37 weeks of gestation, and the rate is increasing since the early 1980 s. $10.6 \%$ neonates born in USA in 1990 were preterm, in the year 2000 the incidence increased to $11.6 \%$ and in 2004 to $12.5 \%$. $^{2}$ In India the incidence of preterm labor is $23.3 \%$ and of preterm delivery is 10 $69 \% .^{3}$ Nowadays progress has been made to improve the survival of premature neonates, mostly by timely interventions, antenatal administration of corticosteroids, better NICU care and exogenous surfactant therapy but still prematurity is the leading cause of neonatal morbidity and mortality. According to Copper et al preterm birth occurs in $7 \%$ to $11 \%$ of pregnancies but is responsible for $85 \%$ of neonatal deaths in normally 
formed infants who do not have any congenital anomalies. ${ }^{4}$ Many conditions and demographic factors are associated with preterm births such as increasing maternal age, increased incidence of underlying health problems such as diabetes and hypertension, greater use of artificial reproductive techniques leading to higher rates of multiple pregnancies and liberal use of caesarean as well as planned inductions before term. The etiology still remains unknown in a large number of cases. ${ }^{5}$

\section{METHODS}

In the present study a total of one hundred pregnant women who delivered before 37 weeks of pregnancy at Maharishi Markandeshwar Institute of Medical Sciences and Research, Mullana from September, 2016 till April, 2017 were included after proper informed consent. All the antenatal patients who had preterm delivery, induced or spontaneous between 28 to 37 weeks of gestation were included in the study. The patients presenting with intrauterine fetal demise and congenital anomalies were excluded in our study. A detailed history of present pregnancy including genitourinary infections, antepartum haemorrhage, hypertension, PPROM, etc was taken. Past medical and surgical history along with past obstetrical history especially of preterm births and abortions was taken to determine the causative factor. Detailed examination general physical, systemic and obstetrical was performed. Gentle per speculum examination was done in all cases and a per vaginum examination was done if needed and Bishop scoring was noted. Risk factors related to preterm labor and neonatal outcome were recorded and analyzed. All investigations including complete haemogram, urine routine examination, urine culture and sensitivity, vaginal culture and sensitivity, ultrasonography and other basic investigations to evaluate the underlying cause of preterm labour was done. Gestational age at the time of delivery, mode of delivery and neonatal outcome in terms of birth weight and apgar score, morbidity and mortality was recorded. Stastical analysis was done using SPSS - 20 version software.

\section{RESULTS}

Present study was conducted on 100 eligible women out of which 7 delivered before 30 weeks but majority of them $(55 \%)$ delivered after 34 weeks of gestation.

In present study, 66\% patients presented in active phase of labor followed by fetal distress $(11 \%)$ which resulted in preterm birth of baby.

Table 1: Gestation at the time of delivery.

\begin{tabular}{|ll|}
\hline Gestational age in weeks & Number \\
\hline 28-30 weeks & 7 \\
\hline $31-34$ weeks & 38 \\
\hline$>34$ weeks & 55 \\
\hline
\end{tabular}

The relationship of preterm birth with maternal age was studied but only 3 cases were more than 35 years of age, so in our study maternal age was not observed as significant risk factor.

Table 2: Cause of preterm delivery.

\begin{tabular}{|l|l|}
\hline Cause & Number \\
\hline Active phase of labor & 66 \\
\hline Antepartum hemorrhage & 10 \\
\hline Acute fetal distress & 11 \\
\hline Severe preeclampsia & 4 \\
\hline Eclampsia & 7 \\
\hline Chorioamnionitis & 2 \\
\hline
\end{tabular}

In present study 61 women were multipara, 30 were primipara and only 9 were grandmultipara. The most common risk factor of preterm labor was genitourinary tract infections (34\%) followed by Preterm Premature rupture of membranes $(22 \%)$.

Table 3: Distribution of subjects according to risk factors.

\begin{tabular}{|ll|}
\hline Risk factors & Number \\
\hline Age & \\
\hline$>35$ years & 3 \\
\hline Parity & \\
\hline Primipara & 30 \\
\hline Multipara & 61 \\
\hline Grandmultipara & 9 \\
\hline Past obstetric history & \\
\hline Abortions & 16 \\
\hline Previous preterm delivery & 8 \\
\hline Present obstetric history & \\
\hline Vaginal infection & 19 \\
\hline UTI & 15 \\
\hline PPROM & 22 \\
\hline Polyhydramnios & 3 \\
\hline Ante partum haemorrhage & 10 \\
\hline Abruption & 7 \\
\hline Placenta praevia & 3 \\
\hline PIH & 21 \\
\hline Multiple pregnancy & 4 \\
\hline Twins & 3 \\
\hline Triplets & 1 \\
\hline Co morbid medical conditions & 6 \\
\hline Severe anaemia & 4 \\
\hline Acute febrile illness & \\
\hline
\end{tabular}

Past obstetric history of preterm delivery and abortions also had a significant impact on the present pregnancy outcome. Past history of abortions was present in 16 patients and 8 patients had history of preterm delivery in previous pregnancies. In present study, antepartum haemorrhage and co-morbid medical conditions were seen in $10 \%$ cases in each group. In present study, 84 neonates required NICU admission. Neonatal mortality 
was seen in 14 cases out of which 13 babies were born before 34 weeks of gestation.

Table 4: Neonatal morbidity and mortality.

\begin{tabular}{|l|l|}
\hline Neonatal Outcome & No. \\
\hline NICU admission & 84 \\
\hline Neonatal mortality & 14 \\
\hline Respiratory distress syndrome & 16 \\
\hline Asphyxia & 18 \\
\hline Jaundice & 30 \\
\hline Septicemia & 9 \\
\hline Necrotising enterocolitis & 1 \\
\hline Hypothermia & 12 \\
\hline Hypoglycemia & 6 \\
\hline
\end{tabular}

Most common ailment associated with preterm neonates was jaundice $(n=30)$ followed by asphyxia which was seen in 18 cases, Respiratory distress syndrome in 16 cases and septicemia in 9 cases. In our study birth weight had significant association with neonatal mortality as all the babies weighing more than 2000 grams survived and both the babies weighing less than 1000 grams expired. Mortality rate was $66.66 \%$ in babies weighing $1000-1499$ grams and $24 \%$ in babies weighing 1500-2000 grams.

Table 5: Association between birth weight and neonatal mortality.

\begin{tabular}{|lll|}
\hline Weight (grams) & Number (total=104) & Mortality \\
\hline$<1000$ & 2 & $2(100 \%)$ \\
\hline $1000-1499$ & 9 & $6(66.66 \%)$ \\
\hline $1500-2000$ & 25 & $6(24 \%)$ \\
$>2000$ & 68 & $0(0 \%)$ \\
\hline
\end{tabular}

\section{DISCUSSION}

Preterm birth is a major challenge in health care and is associated with most of the perinatal deaths. In present study 896 live births took place during study period, out of which $100(11.16 \%)$ patients had preterm delivery. Singh $U$ et al and Satija A et al reported an incidence of $20.9 \%$ and $20.4 \%$ respectively, but they included deliveries at $<28$ weeks of gestation. ${ }^{3,5}$ In present study most common reason for preterm delivery was patients presenting in active phase of labor (66\%) which is comparable to incidence of $68.5 \%$ reported by Singh U et al. ${ }^{3}$ There are multiple factors associated with etiology of preterm labor. Singh $U$ et al found that preterm rupture of membranes was frequently associated with preterm births (25.9\%), we found preterm rupture of membranes to be associated with $22 \%$ preterm births. $^{3}$

Chauhan $\mathrm{N}$ et al also reported PROM as a risk factor in $31.8 \%$ of cases. ${ }^{6}$ The previous obstetrical history was studied as one of risk factors for preterm birth, we found history of preterm delivery in 8 cases and history of abortion in $16 \%$ cases with preterm delivery. History of previous preterm delivery and abortion was observed to be frequently associated with preterm births in various studies, Satija A et al and Singh U et al observed a positive history of previous preterm births in $12 \%$ and $14.4 \%$ cases of preterm labor as respectively. ${ }^{3,5}$ Moreau C et al concluded that previous history of induced increased abortions is associated with preterm births. ${ }^{7}$ In present study infections both vaginal and urinary were seen to be strongly associated with preterm delivery, $19 \%$ of cases had vaginal infection and $15 \%$ had urinary tract infections. Genitourinary infections has been reported to be one of the commonest risk factors in literature, Wright SP et al identified urinary tract infection (UTI) in $7 \%$ of preterm births. ${ }^{8}$ Goldenberg MD et al had also found a strong association between bacterial vaginosis and preterm labor. ${ }^{9}$ Singh $U$ et al found genitourinary infection as the second commonest cause (20.7\%), reporting UTI and vaginal infections in $8.4 \%$ and $12.25 \%$ cases respectively. ${ }^{3}$ Satija A et al found that $26 \%$ patients had vaginal infections and $20 \%$ had UTI. ${ }^{5}$ In present study antepartum haemorrhage was the causative factor in 10 cases of preterm births, out of these 7 patients had abruptio placenta for which termination of pregnancy was done. In a study conducted by Satija a et al antepartum haemorrhage contributed for $11 \%$ cases of preterm birth. ${ }^{5}$ In present study 84 neonates required neonatal intensive care unit (NICU) admission and the most common neonatal complications noted were jaundice (30\%), followed by asphyxia (18\%) and RDS (16\%). Chauhan et al reported the incidence of jaundice $(32.3 \%)$, RDS $(22.6 \%)$ and asphyxia $(13.7 \%)$ in their study. ${ }^{6}$ In present study, neonatal mortality was seen in 14 babies and mortality rate decreased with increasing gestational age, with only 1 mortality in group with more than 34 weeks of gestation, 6 deaths were seen in deliveries before 30 weeks and 7 between 31-34 weeks. Mortality rate of $18.18 \%$ was reported by Venkat $\mathrm{S}$ et al, Satija A et al reported $12.84 \%$ of mortality rate and Sonkusare $S$ et al found the mortality rate to be $14.5 \%$ and mortality rate decreased with gestational age. $5,10,11$ In present study, birth weight had also shown a significant association with mortality as no death was reported in babies born with weight more than 2000 grams.

\section{CONCLUSION}

Preterm labour and birth still have a high incidence causing significant neonatal mortality and morbidity as well as economic burden on family and hospital. The causes of preterm birth are multifactorial and modifiable. This incidence can be reduced by early identification of established risk factors, as revisited and reemphasized in our study, with the help of universal and proper antenatal care. An active and integrated involvement of primary as well as tertiary health sectors can help in achieving this goal.

\section{Funding: No funding sources Conflict of interest: None declared Ethical approval: Not required}




\section{REFERENCES}

1. Blencow H, Cousens S, Oesterguard MZ, Chou D, Moller AB, Narwal R et al. National, regional, and worldwide estimates of preterm birth rates in the year 2010 with time trends since 1990 for selected countries: a systematic analysis and implications. Lancet. 2012;379:2162-72.

2. Gabbe SG, Simpson JL, Niebyl JR. Preterm labour. In: Obstetrics Normal and Problem Pregnancy $5^{\text {th }}$ ed. Elsevier, USA; 668-712.

3. Singh U, Singh N, Seth S. A prospective analysis of etiology and outcome of preterm labor. J Obstet Gynecol India. 2007;57(1):48-52.

4. Copper RL, Goldenberg RL, Creasy RK, DuBard MB, Davis RO, Entman SS et al. A multicenter study of preterm birth weight and gestational age specific neonatal mortality. Am J Obstet Gynecol. 1993;168:78-84.

5. Satija A, Satija V, Kaur J, Bains HS. Prospective analysis of preterm labour: its etiology and outcome. Int J Basic Appl Med Sci. 2014;4(2):70-77.

6. Chauhan N, Purohit RC, Rawat U. Analysis of Etiology and Outcome of Preterm Labour in Tertiary Health Centre of Uttarakhand. Sch J App Med Sci. 2016;4(3B):740-3.
7. Moreau C, Kaminski M, Ancel PY, Bouyer J, Escande B, Thiriez G et al. Previous induced abortions and the risk of very preterm delivery results of EPIPAGE study. BJOG. 2005;112:430-7.

8. Wright SP, Mitchell EA, Thompson JM, Clements MS, Ford RP, Stewart AW. Risk factors for preterm birth; a New Zealand study. NZ Med J. 1998;111:146.

9. Goldenberg MD, Iams JD, Mercer BM, Meis PJ, Moawad AH, Copper RL et al. The preterm prediction study: the value of new vs standard risk factors in predicting early and all spontaneous preterm births. Am J Public Health. 1998;88:233-8.

10. Venkat S, Nayyar R, Bhat J. Retrospective analysis of spontaneous $\mathrm{v} / \mathrm{s}$ induced preterm deliveries and neonatal outcome. J Obstet Gynecol India. 2003;53:46-48.

11. Sonkusare S, Rai L, Naik P. Preterm birth: Mode of delivery and neonatal outcome. Med J Malaysia. 2009;64:303-6.

Cite this article as: Garg S, Kaur T, Saran AS,

Yadav M. A study of etiology and outcome of preterm birth at a tertiary care centre. Int J Reprod Contracept Obstet Gynecol 2017;6:4488-91. 